\title{
Skeletal Maturation Using Cervical Vertebrae Versus Dental Age For Age Estimation
}

\author{
Amal A. El-Bakary ${ }^{1}$, Hend M. Abo El-Atta ${ }^{1}$
}

\begin{tabular}{|c|c|}
\hline & ABSTRACT \\
\hline $\begin{array}{l}\text { KEYWORDS } \\
\text { Mental index, } \\
\text { Willem's method, } \\
\text { CVM staging, } \\
\text { dental age, } \\
\text { Egyptian children. }\end{array}$ & $\begin{array}{l}\text { In forensic science, few data exist regarding cervical vertebrae stages for age } \\
\text { estimation, meanwhile, teeth are frequently used to estimate age. The present study } \\
\text { tested the cervical vertebrae skeletal maturation as an indicator for chronological age. } \\
\text { A total of } 149 \text { radiographs ( } 68 \text { boys and } 81 \text { girls) were analyzed. Their ages ranged } \\
\text { from } 5.94-18.00 \text { years. Cervical vertebral skeletal maturation (CVM) staging and } \\
\text { dental age estimation by Willem's method were estimated. Results show that there is } \\
\text { significant correlation between dental age, CVM and chronological age. However, } \\
\text { CVM staging is not accurate to depend on solely for age estimation especially in } \\
\text { forensic investigations. Willem's method underestimated age by } 0.01 \text { years in girls and } \\
\text { 0.16 years in boys. It can be concluded that CVM can give rough idea about age and } \\
\text { accuracy will be enhanced if combined with dental age estimation. }\end{array}$ \\
\hline
\end{tabular}

\section{Introduction}

Age estimation in children is a fundamental question in forensic medicine; for different civil and criminal cases; as well in cases of mass disaster. Assessment of skeletal maturity is a common application for age estimation in forensic sciences (Mittal et al., 2011). A relationship between the chronological age and the degree of skeletal maturity has been established for several populations e.g. Thai (Krailassiriet al., 2002), Turkish (Uysal etal., 2004), Saudi (AL-Hadlaq et al., 2007a) and Egyptian (El Bakary et al., 2014) children.

Cervical vertebrae skeletal maturation is commonly used by clinical orthodontics to assess skeletal maturity (AL-Hadlaq et al., 2007b, Manica et al., 2013). Hassel and Farman (1995) developed a six-stage- method

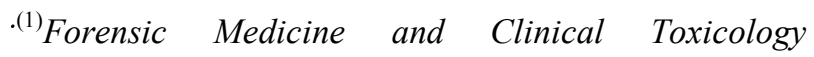
Department, Faculty of Medicine, Mansoura University.
}

for cervical vertebral maturation that has been modified by Baccetti et al. (2002). Many other studies have also been established to assess age through mineralization within acceptable error limits. Willems et al. (2001) adapted a method for dental age estimation in a Belgian Caucasian population. Similarly, El Bakary et al. (2010) proved that it can be applied on Egyptians with $98.62 \%$ accuracy.

In Egypt, the juvenile justice system operates with a specific set of rules and procedures intended to reflect the child's limited responsibility setting the minimum age of criminal responsibility at 12 (Abiad and Mansoor, 2010). It is therefore very important to assess age with accurate and reliable methods to determine whether juvenile penal systems or penal systems in force for adults are to be applied (E1 Bakary et al., 2010).

The aim of this study was to validate the use of cervical vertebrae skeletal maturation as an indicator of chronological age. 


\section{Material and Methods}

This is a retrospective radiographic study for children from six to eighteen-year-old who were treated at the Orthodontics Department, Faculty of Dentistry, Mansoura University from year 2013 to 2014 .

Orthopantograms and lateral cephalograms were collected from files of children. Those radiographs that were unclear or showing any abnormalities were excluded. Those from children with systemic disease that could affect general development like hormonal diseases were excluded from the study.

This study followed the ethical guidelines of the Mansoura University's Research Ethics Committee. Since the radiographs were selected from existing data, there was no risk of additional radiation exposure to patients and patient information was kept anonymous.

\section{Methods}

Age estimation was carried out by two well-trained observers. The interpretations of panoramic and cephalometric radiographs were discussed until agreement was reached (Mittal et al., 2011). Chronological age (CA) was calculated by subtracting the date of the radiograph from the date of birth after having converted both to a decimal age.

\section{Cervical vertebral maturation staging}

Cervical vertebral maturation (CVM) staging was performed according to the method of Baccetti et al. (2005). This method analyzes the morphology of the second (C2), third (C3), and fourth (C4) cervical vertebrae where the patient is classified into one of six stages (Figure 1) as defined below (Table 1).

\section{Dental age estimation:}

Each tooth on the lower left side of the mandible (except the third molar) was given a score from $\mathrm{A}$ to $\mathrm{H}$ depending on its developmental criteria. Maturity scores were then converted into fractions of dental age using conversion tables and then these were summed to obtain dental age (Willems et al., 2001; El Bakary et al., 2010).

\section{Statistical analysis}

All statistics were performed using the SPSS software package (version 16, SPSS Inc., Chicago, IL, USA). Descriptive statistics were obtained by calculating the means and standard deviations of the chronological ages and estimated dental ages for the six stages of CVM. Qualitative variables were described by number and percent. Also, t test was used to compare between readings of two scales. Pearson correlation coefficients were estimated to measure the association between CVM and chronological age, and the statistical significance was set when $\mathrm{p}$ value $<0.05$. Independent $t$ test was used to compare between males and females.

The difference between the means of chronological and estimated dental age was calculated. Positive result indicates an overestimation while the negative is underestimation. 
Table (1): Cervical vertebral maturation stages.

\begin{tabular}{|c|l|}
\hline Stages & \multicolumn{1}{|c|}{ Characters } \\
\hline CS1 & $\begin{array}{l}\text { The lower borders of the } 3^{\text {rd }} \text { vertebrae are flat. The bodies of both the third and fourth } \\
\text { cervical vertebrae (C3 and C4) are trapezoid shaped (the superior border of the vertebral } \\
\text { body is tapered from posterior to anterior). }\end{array}$ \\
\hline CS2 & $\begin{array}{l}\text { The lower border of the } 2^{\text {nd }} \text { cervical vertebra (C2) is concave. The bodies of both C3 and } \\
\text { C4 are still trapezoid-shaped. }\end{array}$ \\
\hline CS3 & $\begin{array}{l}\text { Concavities at the lower borders of both C2 and C3 are present. The bodies of C3 and C4 } \\
\text { can be either trapezoid or rectangular horizontal. }\end{array}$ \\
\hline CS4 & $\begin{array}{l}\text { Concavities at the lower borders of C2, C3, and C4 now are present. The bodies of both } \\
\text { C3 and C4 are rectangular horizontal. }\end{array}$ \\
\hline CS5 & $\begin{array}{l}\text { The concavities at the lower borders of C2, C3, and C4 still are present. At least 1 of the } \\
\text { bodies of C3 and C4 is square. If not square, the body of the other cervical vertebra still } \\
\text { is rectangular horizontal. }\end{array}$ \\
\hline CS6 & $\begin{array}{l}\text { The concavities at the lower borders of C2, C3, and C4 still are evident. At least 1 of the } \\
\text { bodies of C3 and C4 is rectangular vertical. If not rectangular vertical, the body of the } \\
\text { other cervical vertebra is square. }\end{array}$ \\
\hline
\end{tabular}

CS1: Cervical stage 1; CS2: Cervical stage 2; CS3: Cervical stage 3; CS4: Cervical stage 4; CS5: Cervical stage 5; CS6: Cervical stage 6 (Quoted from Baccetti et al., 2005).

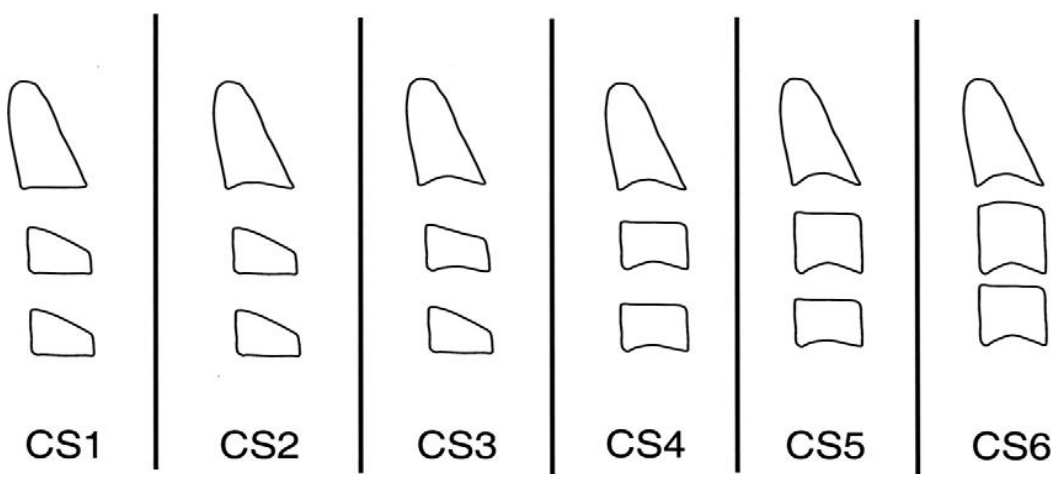

Fig. (1): Schematic representation of the six stages of the Cervical vertebral maturation stages method (Quoted from Baccetti et al., 2005). 


\section{Results}

In the present study, a total of 149 radiographs (68 boys and 81 girls) were analyzed. The age and gender distribution of the sample are shown in table (2). Age of patients ranged from $5.94-18.00(11.70 \pm$ $11.70)$ years. However, their estimated ages by Willems' method ranged from 5.91 - 16.30 $(11.59 \pm 2.43)$ years. The highest number of children was in age group $10-11$ years old $(16.8 \%)$, most of them were boys $(19.1 \%$ of boys); and the least number of children was those between $7-8$ years old $(2.7 \%)$, most of them were girls $(3.7 \%$ of girls). When plotted to cervical maturation stages, the studied cases were mostly represented in stage $1(32.2 \%)$; while least represented in stages 5 and $6(8.7 \%$ each) as shown in table (3).

Dental age estimated by Willem's method showed significant correlation with chronological age both in boys and girls $(p<0.001)$ (Table 4). Mean values of chronological ages and estimated ages by
Willems' method were described in table 5 . There was significant agreement between chronological age and estimated dental age by Willem's method in all cervical maturation stages except in stage six for boys. Mean differences between estimated and chronological ages was -0.01 years in girls and - 0.16 years in boys. The least difference between the means of chronological and estimated dental age was found in cervical stage three in both girls (- 0.002 years) and boys $(0.07$ years $)$. Meanwhile the highest difference was - 0.86 years for boys in stage four.

To show the gender effect, table 6 showed that significant differences between boys and girls in estimated dental age by William's method were observed in stages three, five and six.

The inter-observer reliability conducted on 20 subjects ( 10 boys and 10 girls) that were re-evaluated after an interval of at least 2 week, showed that Cronbach's Alpha test was 0.95 for dental estimation and 0.92 for cervical staging.

Table (2): Age and sex distribution among the studied group ( $\mathrm{n}=149)$.

\begin{tabular}{|c|c|c|c|}
\hline \multirow{2}{*}{ Age groups } & \multicolumn{2}{|c|}{ Sex } & \multirow{2}{*}{ Total } \\
\cline { 2 - 3 } & Girls & Boys & $6(4.0 \%)$ \\
\hline $\mathbf{6 - 7} \mathbf{y}$ & $3(3.7 \%)$ & $3(4.4 \%)$ & $4(2.7 \%)$ \\
\hline $\mathbf{7 - 8} \mathbf{y}$ & $3(3.7 \%)$ & $1(1.5 \%)$ & $10(6.7 \%)$ \\
\hline $\mathbf{8 - 9} \mathbf{y}$ & $6(7.4 \%)$ & $4(5.9 \%)$ & $17(11.4 \%)$ \\
\hline $\mathbf{9 - 1 0} \mathbf{y}$ & $11(13.6 \%)$ & $6(8.8 \%)$ & $25(16.8 \%)$ \\
\hline $\mathbf{1 0 - 1 1} \mathbf{y}$ & $12(14.8 \%)$ & $13(19.1 \%)$ & $24(16.1 \%)$ \\
\hline $\mathbf{1 1 - 1 2} \mathbf{y}$ & $14(17.3 \%)$ & $10(14.7 \%)$ & $14(9.4 \%)$ \\
\hline $\mathbf{1 2 - 1 3} \mathbf{y}$ & $10(12.3 \%)$ & $4(5.9 \%)$ & $14(9.4 \%)$ \\
\hline $\mathbf{1 3 - 1 4} \mathbf{y}$ & $6(7.4 \%)$ & $8(11.8 \%)$ & $15(10.1 \%)$ \\
\hline $\mathbf{1 4 - 1 5} \mathbf{y}$ & $8(9.9 \%)$ & $7(10.3 \%)$ & $10(6.7 \%)$ \\
\hline $\mathbf{1 5 - 1 6} \mathbf{y}$ & $5(6.2 \%)$ & $5(7.4 \%)$ & $10(6.7 \%)$ \\
\hline $\mathbf{1 6 - 1 8} \mathbf{y}$ & $3(3.7 \%)$ & $7(10.3 \%)$ & $149(100.0 \%)$ \\
\hline Total & $81(100.0 \%)$ & $68(100.0 \%)$ & \\
\hline & & & \\
\hline
\end{tabular}


Table (3): Sex distribution of the studied groups according to cervical stages (CVMI).

\begin{tabular}{|c|c|c|c|c|c|c|c|}
\hline & $\begin{array}{c}\text { Stage 1 } \\
\text { n (\%) }\end{array}$ & $\begin{array}{c}\text { Stage 2 } \\
\mathbf{n}(\%)\end{array}$ & $\begin{array}{c}\text { Stage 3 } \\
\mathbf{n}(\%)\end{array}$ & $\begin{array}{c}\text { Stage 4 } \\
\mathbf{n}(\%)\end{array}$ & $\begin{array}{c}\text { Stage 5 } \\
\mathbf{n}(\%)\end{array}$ & $\begin{array}{c}\text { Stage 6 } \\
\mathbf{n}(\%)\end{array}$ & Total \\
\hline Boys & $26(38.2 \%)$ & $13(19.1 \%)$ & $\begin{array}{c}7 \\
(10.3 \%)\end{array}$ & $11(16.2 \%)$ & $\begin{array}{c}7 \\
(10.3 \%)\end{array}$ & $\begin{array}{c}4 \\
(5.9 \%)\end{array}$ & $\begin{array}{c}68 \\
(100.0 \%)\end{array}$ \\
\hline Girls & $22(27.2 \%)$ & $12(14.8 \%)$ & $14(17.3 \%)$ & $18(22.2 \%)$ & $\begin{array}{c}6 \\
(7.4 \%)\end{array}$ & $\begin{array}{c}9 \\
(11.1 \%)\end{array}$ & $\begin{array}{c}81 \\
(100.0 \%)\end{array}$ \\
\hline Total & $48(32.2 \%)$ & $25(16.8 \%)$ & $21(14.1 \%)$ & $29(19.5 \%)$ & $\begin{array}{c}13 \\
(8.7 \%)\end{array}$ & $\begin{array}{c}13 \\
(8.7 \%)\end{array}$ & $\begin{array}{c}149 \\
(100.0 \%)\end{array}$ \\
\hline
\end{tabular}

$\mathrm{n}=$ number, $\%=$ percentage within $\mathrm{sex}$.

Table (4): Correlation between chronological age and estimated dental age by William's method.

\begin{tabular}{|c|c|c|c|}
\hline & $\begin{array}{c}\text { Boys } \\
(\mathbf{n}=\mathbf{6 8})\end{array}$ & $\begin{array}{c}\text { Girls } \\
(\mathbf{n}=\mathbf{8 1})\end{array}$ & $\begin{array}{c}\text { Total } \\
(\mathbf{n}-149)\end{array}$ \\
\hline $\mathrm{r}$ & 0.939 & 0.922 & 0.931 \\
\hline $\mathrm{p}$ & $<0.001^{*}$ & $<0.001^{*}$ & $<0.001^{*}$ \\
\hline
\end{tabular}

n: number, *: significant at $\mathrm{p}<0.05$.

Table (5): Mean values of chronological ages, estimated dental age by William's method, mean difference values and test of agreement between chronological ages and estimated dental age of the studied group $(\mathrm{n}=149)$ in relation to cervical stages.

\begin{tabular}{|c|c|c|c|c|c|c|c|c|c|c|}
\hline \multirow{2}{*}{$\begin{array}{l}\text { CVMI } \\
\text { stages }\end{array}$} & \multirow{2}{*}{ Gender } & \multirow{2}{*}{$\mathbf{n}$} & \multicolumn{2}{|c|}{ Chronological age } & \multicolumn{2}{|c|}{$\begin{array}{l}\text { Estimated dental age } \\
\text { (Willem's method) }\end{array}$} & \multirow{2}{*}{ Error } & \multirow{2}{*}{$\begin{array}{c}\text { P } \\
\text { VALUE }\end{array}$} & \multicolumn{2}{|c|}{ Test of agreement } \\
\hline & & & Range & mean \pm SD & Range & mean \pm SD & & & $\mathbf{r}$ & $\mathbf{p}$ \\
\hline \multirow{2}{*}{ Stage 1} & $\mathrm{M}$ & 26 & $5.94-14.73$ & $10.09 \pm 2.02$ & $5.91-13.94$ & $10.39 \pm 1.9$ & 0.30 & 0.5 & 0.921 & $<0.001^{*}$ \\
\hline & F & 22 & $5.95-16.04$ & $9.51 \pm 2.14$ & $6.30-15.79$ & $9.76 \pm 2.3$ & 0.24 & 0.7 & 0.914 & $<0.001^{*}$ \\
\hline \multirow{2}{*}{ Stage 2} & $\mathrm{M}$ & 13 & $8.00-12.95$ & $10.46 \pm 1.31$ & $7.11-13.59$ & $10.27 \pm 1.76$ & -0.19 & 0.7 & 0.832 & $<0.001^{*}$ \\
\hline & $\mathrm{F}$ & 12 & $8.00-13.00$ & $10.49 \pm 1.27$ & $7.78-13.70$ & $10.61 \pm 1.52$ & 0.12 & 0.8 & 0.793 & $0.002^{*}$ \\
\hline \multirow{2}{*}{ Stage 3} & $\mathrm{M}$ & 7 & $10.20-16.08$ & $13.29 \pm 2.01$ & $9.54-16.03$ & $13.36 \pm 2.17$ & 0.07 & 0.9 & 0.951 & $0.001^{*}$ \\
\hline & F & 14 & $6.34-14.07$ & $10.72 \pm 1.96$ & $6.39-13.84$ & $10.72 \pm 2.03$ & -0.002 & 1.00 & 0.929 & $<0.001^{*}$ \\
\hline \multirow{2}{*}{ Stage 4} & M & 11 & $10.92-16.45$ & $13.91 \pm 1.44$ & $11.55-16.03$ & $13.05 \pm 1.23$ & -0.86 & 0.14 & 0.623 & $0.04^{*}$ \\
\hline & $\mathrm{F}$ & 18 & $11.07-15.67$ & $13.40 \pm 1.38$ & $10.98-15.79$ & $13.34 \pm 1.26$ & -0.07 & 0.9 & 0.754 & $<0.001^{*}$ \\
\hline \multirow{2}{*}{ Stage 5} & M & 7 & $14.25-18.00$ & $15.77 \pm 1.41$ & $13.53-16.30$ & $15.12 \pm 1.24$ & -0.65 & 0.37 & 0.901 & $0.006^{*}$ \\
\hline & $\mathrm{F}$ & 6 & $7.92-15.37$ & $12.53 \pm 2.99$ & $8.44-15.79$ & $11.92 \pm 2.6$ & -0.62 & 0.7 & 0.875 & $0.02^{*}$ \\
\hline \multirow{2}{*}{ Stage 6} & M & 4 & $14.15-18.00$ & $15.99 \pm 1.58$ & $14.34-16.03$ & $15.31 \pm 0.85$ & -0.68 & 0.47 & 0.819 & 0.18 \\
\hline & $\mathrm{F}$ & 8 & $11.32-17.31$ & $13.59 \pm 2.04$ & $10.67-15.79$ & $12.94 \pm 1.43$ & -0.18 & 0.47 & 0.854 & $0.007^{*}$ \\
\hline \multirow{2}{*}{ Total } & M & 68 & $5.94-18.00$ & $12.04 \pm 2.81$ & $5.91-16.30$ & $11.88 \pm 2.53$ & -0.16 & 0.7 & 0.939 & $<0.001^{*}$ \\
\hline & $F$ & 81 & $5.95-17.31$ & $11.41 \pm 2.48$ & $6.30-15.79$ & $11.34 \pm 2.33$ & -0.01 & 0.8 & 0.922 & $<0.001^{*}$ \\
\hline
\end{tabular}

CVMI: cervical stages, M: boys, F: girls, SD: standard deviation, error: mean differences between estimated and chronological ages. 
Table (6): Gender difference of estimated dental age by William's method in relation to cervical stages (CVMI) $(\mathrm{n}=149)$.

\begin{tabular}{|c|c|c|c|c|}
\hline \multirow{2}{*}{ CVMI stages } & $\begin{array}{c}\text { Mean difference } \\
\text { between boys and girls }\end{array}$ & \multirow{2}{*}{$\mathbf{p}$ value } & $\begin{array}{c}\mathbf{9 5 \%} \text { confidence } \\
\text { interval }\end{array}$ & $\begin{array}{c}\mathbf{9 5 \%} \text { confidence } \\
\text { interval }\end{array}$ \\
\cline { 3 - 5 } & & Lower & Upper \\
\hline Stage 1 & 0.62 & 0.3 & -0.60 & -0.60 \\
\hline Stage 2 & -0.34 & 0.6 & -1.7 & -1.7 \\
\hline Stage 3 & 2.64 & $0.01^{*}$ & 0.62 & 0.62 \\
\hline Stage 4 & -0.29 & 0.5 & -1.2 & -1.2 \\
\hline Stage 5 & 3.2 & $0.01^{*}$ & 0.75 & 0.75 \\
\hline Stage 6 & 2.36 & $0.01^{*}$ & 0.609 & 0.609 \\
\hline
\end{tabular}

CVMI: cervical stages

\section{Discussion}

In forensic medicine, it is becoming increasingly necessary to have tools capable to estimate individual's age as accurate as possible. The present study tested the cervical vertebrae skeletal maturation as an indicator for chronological age. Results show that the range of age is wide and overlapping in each stage. So, it is not accurate to depend only on cervical maturation stages for age estimation especially in forensic investigations. Hence, dental age was estimated using Willem's method and correlated to each skeletal maturation stage.

It was shown that dental age estimated by Willem's method has significant correlation with chronological age in all cervical stages. This augments previous results in Egyptian (El Bakary et al., 2010), Indian (Mohammed et al., 2014) and Turkish (Altan et al., 2016) populations. Willems' method showed under-estimation in boys by 0.16 years and in girls by -0.01 years. The least difference is $-0.002 \mathrm{y}$ in girls in stage three while the highest is $-0.86 \mathrm{y}$ in boys in stage four. In spite of over-estimation $(0.15$ years) that was reported in more or less similar Egyptian population (El Bakary et al., 2010), under-estimation encountered in the present work (although figures are nearly similar) may be due to relatively smaller sample size.

Similarly, under aging assessed by Willems method was reported for both boys and girls in Bangladeshi and British Caucasians (Maber et al., 2006) and in Indians (Mohammed et al., 2014; Patnana et al., 2014). Meanwhile, over-estimation of age was reported by Mani et al. (2008) in Malays (0.55 and 0.41 years among boys and girls, respectively) and by Pinchiet al. (2012) in Italians. These differences may be due to difference in sample size, age groups, the age and sex distribution of the original study population and statistical methodologies (Mohammed et al., 2014).

As previously reported for Malay (Ann et al., 2008), Egyptian (El Bakary et al., 2010) and Turkish (Altan et al., 2016) children, the present study showed that dental age estimation is more accurate in girls. On the other hand, better accuracy was reported in Iranian (Bagherian and Sadeghi, 2011) and in Belgian Caucasian (Willems et al., 2001) boys.

The appearance of each stage is earlier in girls in CVMI stages three, five and six while boys have nearly the same range as girls in stages one, two and four. This may be due to faster skeletal development in adolescent girls as previously reports (Krailassiri et al., 2002; Mittal et al., 2011; Manica et al., 2013) or due to the relatively smaller number of boys compared 
to girls in these stages. In the same time, dental age estimated by Willems' method shows significant faster dental development in girls compared to boys in cervical stages three, five and six. This faster development in girls especially in older age groups $(10-17$ years) may be due to hormonal factors.

It is important to realize that no age estimation method will accurately determine the exact age for every individual since development naturally varies between individuals. Moreover, one should not restrict to only one age estimation technique, but to apply different techniques available (Mohammed et al., 2014).

Based on the results of this research, it can be concluded that there is significant correlation between cervical vertebral skeletal maturation and chronological age. In the same time results suggest that CVM can give rough idea about age and accuracy will be enhanced if combined with dental age estimation.

\section{References}

Abiad, N. and Mansoor, F. (2010): "Ciminal law and the rights of the child in the muslim states". British Institute of International and Comparative Law (BIICL), P.P. 395.

AL-Hadlaq, A.; Al-Qarni, M.; Al Kahtani, A.; et al. (2007b): "Comparative study between hand-wrist method and cervical vertebral maturation method for evaluation of skeletal maturity in Saudi boys". Pakistan Oral \& Dental Journal, 27: 187-192.

AL-Hadlaq, A.; Hashim, H.; AL-Shalan, T.; et al. (2007a): "Association between chronologicaland skeletal ages among a sample of Saudi male children". Saudi Dent J., 19: 1-7.
Altan, H.O.; Altan, A.; Bilgiç, F.; et al. (2016): "The applicability of Willems' method for age estimation in southern Turkish children: A preliminary study". J. Forensic Leg. Med., 38:24-27.

Ann, M.S.; Lin, N.; Jacob, J.; et al. (2008): "Comparison of two methods of dental age estimation in 7-15-year-old Malays". International Journal of Pediatric Dentistry, 18(5):380-388.

Baccetti, T.; Franchi, L. and McNamara, J.A. (2002): "An improved version of the cervical vertebral maturation (CVM) method for the assessment of mandibular growth". Angle Orthod., 72(4):316-323.

Baccetti, T.; Franchi, L. and McNamara, J.A. (2005): "The cervical vertebral maturation (CVM) method for the assessment of optimal treatment timing in dentofacial orthopedics". Semin. Orthod., 11: 119-129.

Bagherian, A. and Sadeghi, M. (2011): "Assessment of dental maturity of children aged 3.5 to 13.5 years using the Demirjian method in an Iranian population". Journal of Oral Science, 53 (1): 37-42.

El Bakary, A.A.; Attalla, S.M.; Hammad, S.M.; et al. (2014): "Age estimation in Egyptian children by measurements of carpals and epiphyses of the ulna and radius". Journal of Forensic Radiology and Imaging, 2: $121-125$.

El Bakary, A.A.; Hammad, S.M. and Mohammed, F. (2010): "Dental age estimation in Egyptian children, comparison between two methods". J. Forensic Leg. Med., 17: 363-367.

Hassel, B. and Farman, A.G. (1995): "Skeletal maturation evaluation using cervical vertebrae". Am. J. Orthod Dentofacial Orthop., 107:58-66. 
Krailassiri, S.; Anuwongnukroh, N. and Dechkunakorn, S. (2002): "Relationship between dental calcification stages and skeletal maturity indicators in Thai individuals". Angle Orthod., 72:155166.

Maber, M.; Liversidge, H.M. and Hector, M.P. (2006): "Accuracy of age estimation of radiographic methods using developing teeth". Forensic Science International, 15:68-73.

Mani, S.A.; Naing, L.; John, J.; et al. (2008): "Comparison of two methods of dental age estimation in 7-15-yearold Malays". Int. J. Paediatr. Dent., 18:380-388.

Manica, S.; Liversidge, H. and Wong, F. (2013): "A pilot study on maturation of cervical vertebrae and permanent teeth". Journal of Forensic Odontostomatology, 31: 147, Abstract book IOFOS Conference 2013.

Mittal, S.K.; Singla, A.; Virdi, M.S.; et al. (2011): "Corelation between determination of skeletal maturation using cervical vertebrae and dental calcification stages". The Internet
Journal of Forensic Science, 4: 15402622.

Mohammed, R.B.; Krishnamraju, P.V.; Prasanth, P.S.; et al. (2014): "Dental age estimation using Willems method: A digital orthopantomographic study". Contemp. Clin. Dent., 5: 371-376.

Patnana, A.K.; Vabbalareddy, R.S. and Vanga, N.R.V. (2014): "Evaluating the reliability of three different dental age estimation methods in visakhapatnam children". Int. J. Clin. Pediatr. Dent.,7:186-191.

Pinchi, V.; Norelli, G.A.; Pradella, F.; et al. (2012): "Comparison of the applicability of four odontological methods for age estimation of the 14 years legal threshold in a sample of Italian adolescents". J. Forensic Odontostomatol., 30:17-25.

Uysal, T.; Sari, Z.; Ramoglu, S.I.; et al. (2004): "Relationships between dental and skeletal maturity in Turkish subjects". Angle Orthod., 74: 657-664.

Willems, G.; Van Olmen, A.; Spiessens, B.; et al. (2001): "Dental age estimation in Belgian children: Demirjian's technique revisited". Journal of Forensic Science, 46:893-895. 


\section{تقدير العمر عن طريق نضوج الهيكل العظمي لفقرات العنق مقابل العمر السني}

\section{امال عبلد السلام البقري - هند محمود ابو العطا}

قسم الطب الثرعي والسموم الإكلينيكية ـ كلية الطب- جامعة المنصورة

يوجد في علم الطب الثر عي القليـل مـن البيانـات عن استخدام مر احل نضوج الفقرات العنقبـة لتقدير

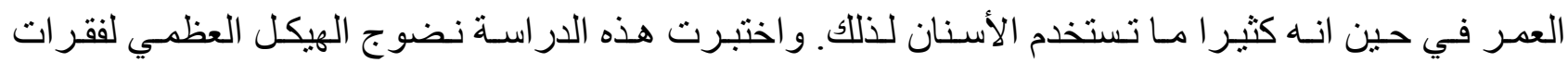

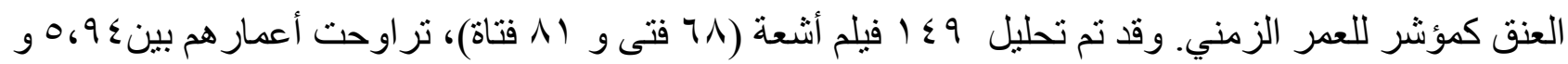

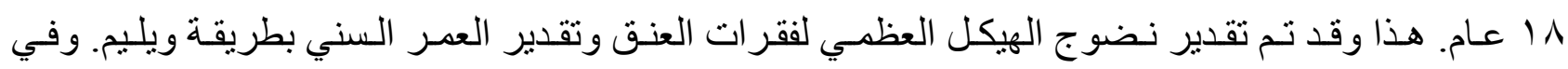
الوقت الذي اظهرت فيه النتائج أن هناك ارتباط كبير بين كل من العمر السني و نضوج الهيكل العظمي لفقرات

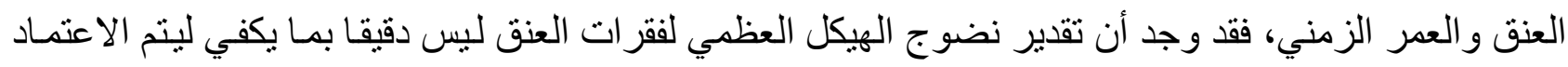
عليه في تقدير العمر خصوصا في تحقيقات الطب الشرعي. و قد وجد أن طريقة ويليم لتقدير العمر السني قد فئ

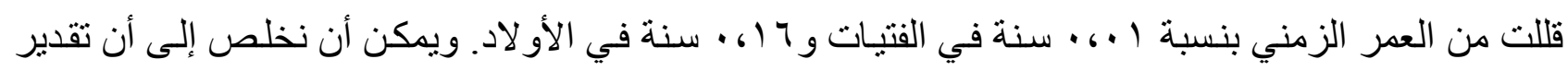
نضوج الهيكل العظمي لفقرات العنق يمكن أن يعطي فكرة تقريبية عن العمر ويمكن تعزيز دقته باقتر انه بتقدير العمر السني. 